\title{
INFLUENCE OF CARBON AND NICKEL ON SURFACE PROPERTIES OF Fe-C-O-X (X=Cr, Ni) ALLOYS
}

\author{
Vlastimil NOVÁK, Lenka ŘEHÁČKOVÁ, Bedřich SMETANA, Silvie ROSYPALOVÁ, \\ L'ubomíra DROZDOVÁ
}

VSB -Technical University of Ostrava, Ostrava, Czech Republic, EU, vlastimil.novak@vsb.cz

https://doi.org/10.37904/metal.2019.676

\begin{abstract}
This paper deals with an experimental determination of surface tension, densities and wetting angles, which were considered for spreading on an alumina substrate, of selected $\mathrm{Fe}-\mathrm{C}-\mathrm{O}-\mathrm{X}(\mathrm{X}=\mathrm{Cr}, \mathrm{Ni})$ alloys. The concerned physico-chemical quantities were determined by a sessile drop method in the temperature interval between liquidus temperature of the given alloy and temperature of $1,600{ }^{\circ} \mathrm{C}$ during heating with a rate of $5{ }^{\circ} \mathrm{C} \cdot \mathrm{min}^{-1}$. Several Fe-C-O-Cr and Fe-C-O-Ni model alloys differed in carbon (0.043-1.378 wt.\%) and nickel (1.084 - $4.478 w t . \%)$ content in order to assess the effect of these elements. From the dependence of surface tension on temperature, it was found that the surface tension of given alloys increases slightly with increasing temperature, i.e. that the temperature coefficient of surface tension $d \sigma / d T$ was positive. Similar course was ascribed regarding wetting angles dependence on temperature. Further, the influence of carbon and nickel on surface properties was proved by statistical analysis carried out in the R environment for statistical computing and visualization.
\end{abstract}

Keywords: Surface tension, wettability, sessile drop method, iron alloy

\section{INTRODUCTION}

Knowledge of thermodynamic quantities of iron-based alloys covers various areas of materials science and engineering. One of these variables is surface tension, which provides information related to several different phenomena concerning refining, casting, welding processes, including the separation of inclusions from steel to slag, spreading inclusions and others. If the surface tension is experimentally determined by one of the contact methods, e.g. a sessile drop method, another significant surface property, namely wettability, is closely linked to it. Experimental determination of both properties at high temperatures is challenging since metal melt interacts with solid ceramic substrates whose chemical heterogeneity, roughness and porosity can significantly affect wettability. Thus, surface tension is very sensitive to even modest contamination of metal sample surface.

The surface properties of metal alloys are, in particular, dependent on temperature and chemical composition. Many authors have already addressed the influence of impurities on surface tension. Lee and Morita [1] argued that carbon enhances the activity of sulfur and therefore reduces the surface tension of the metal melt. However, Morohoshi et al. [2] provided that the surface tension of the Fe-C melt remains constant in carbon activity of between 0.1 and 0.73 . Based on a study of Kawai et al. [3], it can be considered that carbon acts as a surface-active element, i.e. it reduces the surface tension of steel. Jimbo and Cramb [4] claimed that higher carbon content causes a small increase in the surface tension of molten iron. Regarding the effect of nickel on the surface tension of alloys, it is well described, especially for binary systems in whose it can also be estimated as outlined by McNallan [5]. In a multicomponent alloy, alloying elements that affect surface tension are segregated to the surface. Nickel belongs among elements which tend to segregate onto alloy surface. Nonetheless, since the magnitudes of energy changes accompanied by the segregation are relatively smaller than those of strongly surface-active elements like sulphur and oxygen, their effect is significantly less [6]. For binary alloys, the calculations based on the Gibbs energy minimization method showed that an increase in nickel mole fraction lowers surface tension [7]. Measurement of undercooled binary iron-nickel alloys over a 
wide concentration range as a function of concentration indicated the similar tendency of nickel acting as a surface-active element [8]. Further, the nickel addition to the iron-nickel alloy increases surface tension, due to its ability to lower surface active behaviour of oxygen [9]. In summary, the effect of carbon is inconclusive, and the same applies to nickel mainly in the case of multicomponent systems.

The presented work is focused on the experimental study of the influence of temperature and admixed elements (carbon and nickel) on surface tension, density and wettability of selected $\mathrm{Fe}-\mathrm{C}-\mathrm{O}-\mathrm{X}(\mathrm{X}=\mathrm{Cr}$, Ni) model alloys varying in carbon (0.043 - $1.378 \mathrm{wt} . \%)$ and nickel (1.084 - $4.478 \mathrm{wt} . \%)$ content. The surface properties were determined by the sessile drop method when the molten alloy was in contact with the alumina substrate.

\section{EXPERIMENTAL RESEARCH}

\subsection{Preparation of alloy samples}

Six alloys (samples 1 - 6) were selected for the measurement of the surface tension by the sessile drop method. These samples were prepared from pure metals and $\mathrm{Fe}_{2} \mathrm{O}_{3}$ tablets with the use of vacuum induction melting. Chemical composition, listed in Table 1, was determined by GDA 750 HP optical emission spectrometer (GDOES) and combustion analysers Eltra $2000 \mathrm{CS}$ and Eltra $2000 \mathrm{ONH}$. Prior to the experiment, alloy samples of cylindrical shape (5 mm diameter x $5 \mathrm{~mm}$ height) were thoroughly mechanically cleaned to remove surface oxides. For the purposes of the experiment, alumina plates $\left(99.8 \% \mathrm{Al}_{2} \mathrm{O}_{3}\right)$ were annealed at $1,150{ }^{\circ} \mathrm{C}$ for 6 hours, and their surface was cleaned by acetone immediately preceding the measurement.

Table 1 Composition of alloy samples (wt. \%)

\begin{tabular}{|c|c|c|c|c|c|c|c|c|c|c|}
\hline Sample & $\mathbf{C}$ & $\mathbf{N i}$ & $\mathbf{C r}$ & $\mathbf{O}$ & $\mathbf{S}$ & $\mathbf{M n}$ & $\mathbf{W}$ & $\mathbf{C o}$ & $\mathbf{C u}$ & $\mathbf{A l}$ \\
\hline $\mathbf{1}$ & 0.042 & 0.002 & 4.883 & 0.026 & 0.052 & 0.051 & - & 0.017 & 0.006 & - \\
\hline $\mathbf{2}$ & 0.650 & 0.001 & 4.671 & 0.019 & 0.053 & 0.047 & 0.036 & 0.021 & 0.007 & 0.009 \\
\hline $\mathbf{3}$ & 1.378 & $<0.001$ & 4.591 & 0.011 & 0.054 & 0.047 & 0.038 & 0.021 & 0.007 & 0.007 \\
\hline $\mathbf{4}$ & 0.382 & 1.084 & 0.010 & 0.002 & 0.006 & 0.030 & $<0.001$ & $<0.001$ & 0.014 & 0.010 \\
\hline $\mathbf{5}$ & 0.375 & 2.990 & 0.012 & 0.003 & 0.006 & 0.086 & $<0.001$ & $<0.001$ & 0.009 & 0.011 \\
\hline $\mathbf{6}$ & 0.338 & 4.478 & 0.010 & 0.001 & 0.006 & 0.031 & $<0.001$ & $<0.001$ & 0.012 & 0.011 \\
\hline
\end{tabular}

Content of other elements was less than 0.005 wt. \%

\subsection{Measurement of surface properties}

Experimental determination of surface tension by the sessile drop method was performed in the observation high-temperature furnace Clasic. The temperature range was chosen between the melting point and temperature of $1,600{ }^{\circ} \mathrm{C}$. Alloy samples were placed in the furnace, which was then hermetically sealed, evacuated to approximately $0.1 \mathrm{~Pa}$ and washed with argon (>99.9999\%). The heating rate was $5{ }^{\circ} \mathrm{C} \cdot \mathrm{min}^{-1}$, and the temperature was measured by a thermocouple $\mathrm{Pt}-13 \% \mathrm{Rh} / \mathrm{Pt}$. The experiment was carried out under an inert atmosphere of argon to prevent oxidation of the sample during measurement. The images of the droplet forming process were captured by a CANON EOS20D and saved in the PC. The statistical analysis of surface tension measurements was carried out by the computing environment $R$ ( $R$ Development Core Team, 2018).

\section{RESULTS AND DISCUSSION}

Two series of model alloys were chosen to assess the influence of carbon and nickel on the surface properties and densities of investigated alloys. Three alloys denoted Fe-C-O-Cr (samples 1 - 3 ) differed in carbon content (0.043 - 1.378 wt. \%), and remaining alloys signed Fe-C-O-Ni (samples 4 - 6) varied in nickel content (1.084 - 
4.478 wt.\%). Figures 1 and 2 show the temperature dependencies of the average surface tension of both model series. As can be seen from the figures, the surface tension increases slightly with rising temperature, i.e. the temperature coefficient of the surface tension $d \sigma / d T$ is positive (see Table 2). Positive surface tension coefficient value can be attributed to the presence of surface-active elements oxygen and sulfur [10].

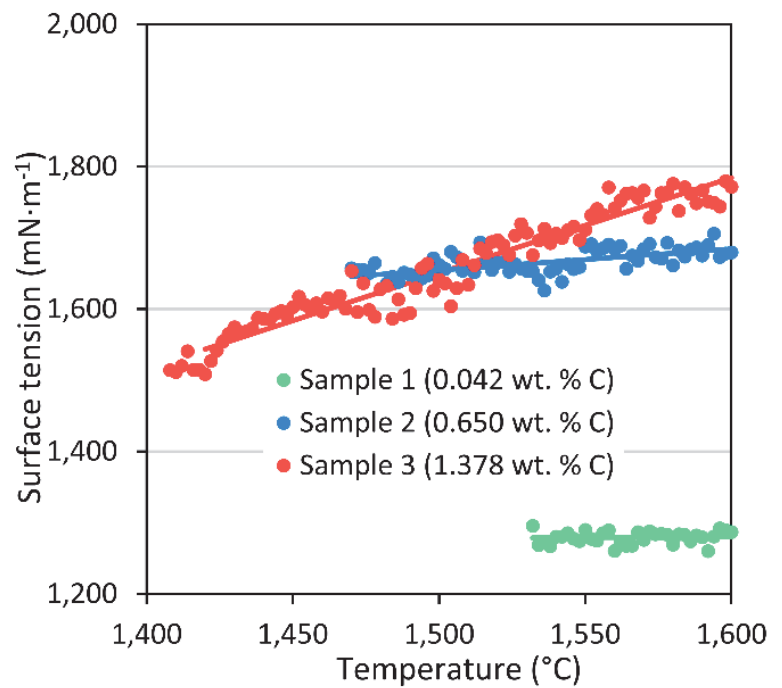

Figure 1 Temperature dependencies of average surface tension for Fe-C-O-Cr alloys

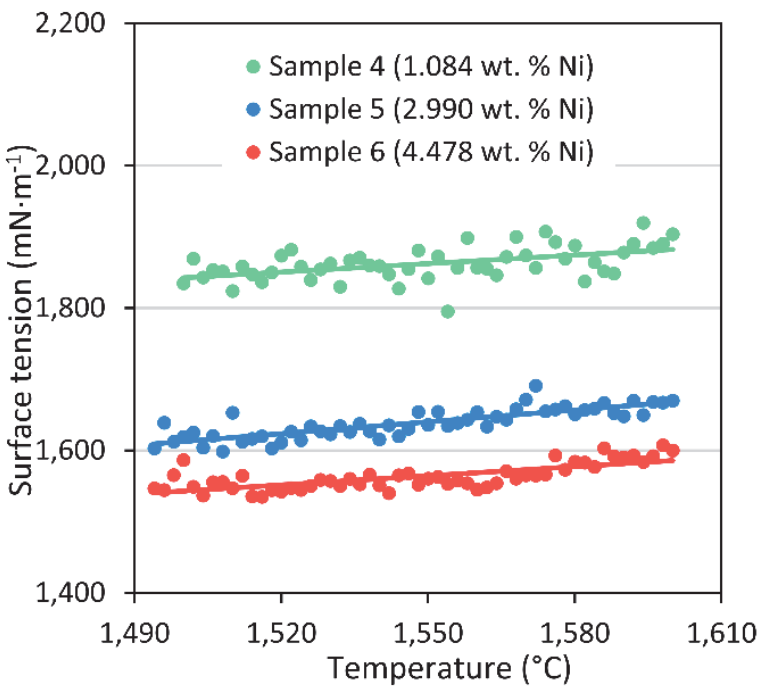

Figure 2 Temperature dependencies of average surface tension for Fe-C-O-Ni alloy

Using equation (1), the surface tension can be expressed as a function of temperature. Calculated parameters are listed in Table 2.

$\sigma(T)=\sigma_{\text {ref }}+\frac{d \sigma}{d T} \cdot\left(T-T_{\text {ref }}\right)$

where $\sigma_{\text {ref }}\left(\mathrm{mN} \cdot \mathrm{m}^{-1}\right)$ is surface tension at reference temperature $T_{\text {ref }}\left({ }^{\circ} \mathrm{C}\right), d \sigma / d T\left(\mathrm{mN}^{-} \mathrm{m}^{-1 .}{ }^{\circ} \mathrm{C}^{-1}\right)$ denotes temperature coefficient of surface tension.

Table 2 Linear correlation parameters of surface tension and density for alloy samples 1-6

\begin{tabular}{|c|c|c|c|c|c|c|}
\hline Sample & $T_{\text {ref }}\left({ }^{\circ} \mathbf{C}\right)$ & $\sigma_{\text {ref }}\left(\mathbf{m N} \cdot \mathbf{m}^{-1}\right)$ & $d \sigma / d T\left(\mathbf{m N} \cdot \mathbf{m}^{-1} \cdot{ }^{\circ} \mathbf{C}^{-1}\right)$ & $\rho_{\text {ref }}\left(\mathbf{g} \cdot \mathbf{c m}^{-3}\right)$ & $d \rho / d T\left(\mathbf{g}^{\prime} \mathbf{c m}^{-3} \cdot{ }^{\circ} \mathbf{C}^{-1}\right)$ & $\Delta T\left({ }^{\circ} \mathbf{C}\right)$ \\
\hline $\mathbf{1}$ & 1,532 & 1,277 & $0.61 \cdot 10^{-1}$ & 7.34 & $-0.54 \cdot 10^{-3}$ & $1,532-1,600$ \\
\hline $\mathbf{2}$ & 1,470 & 1,646 & $2.98 \cdot 10^{-1}$ & 7.21 & $-1.09 \cdot 10^{-3}$ & $1,470-1,600$ \\
\hline $\mathbf{3}$ & 1,408 & 1,527 & $13.9 \cdot 10^{-1}$ & 7.09 & $-1.42 \cdot 10^{-3}$ & $1,408-1,600$ \\
\hline $\mathbf{4}$ & 1,500 & 1,843 & $3.96 \cdot 10^{-1}$ & 6.95 & $-1.03 \cdot 10^{-3}$ & $1,500-1,600$ \\
\hline $\mathbf{5}$ & 1,494 & 1,609 & $5.53 \cdot 10^{-1}$ & 7.23 & $-0.96 \cdot 10^{-3}$ & $1,494-1,600$ \\
\hline $\mathbf{6}$ & 1,492 & 1,540 & $4.29 \cdot 10^{-1}$ & 7.26 & $-0.74 \cdot 10^{-3}$ & $1,492-1,600$ \\
\hline
\end{tabular}

The normality of the measured data was assessed by the Shapiro-Wilk test, according to which they were not normally distributed. The models for samples 1 and 4 were not statistically significant at the significance level of $5 \%$ according to total F-test, implying that the surface tension was almost constant in the given temperature ranges. The influence of carbon and nickel content on surface tension was evaluated by the Kruskal-Wallis test proving statistically significant effect since the $p$-value was less than 0.001 , i.e. the differences in surface tension were statistically significant at all observed carbon and nickel levels. Furthermore, Dunn's test demonstrated that no two samples had comparable surface tension ( $p$-values $<<0.001$ ). Figures 3 and 4 supports these findings showing that carbon increased surface tension and nickel acted differently. 


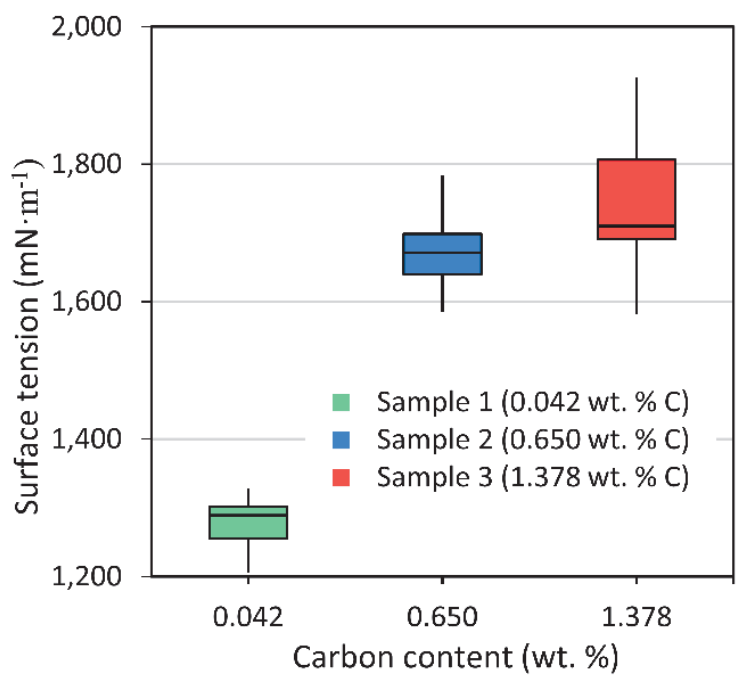

Figure 3 Boxplot of carbon effect on surface tension for $\mathrm{Fe}-\mathrm{C}-\mathrm{O}-\mathrm{Cr}$ alloys, temperature range 1,532 -

$$
1,600^{\circ} \mathrm{C}
$$

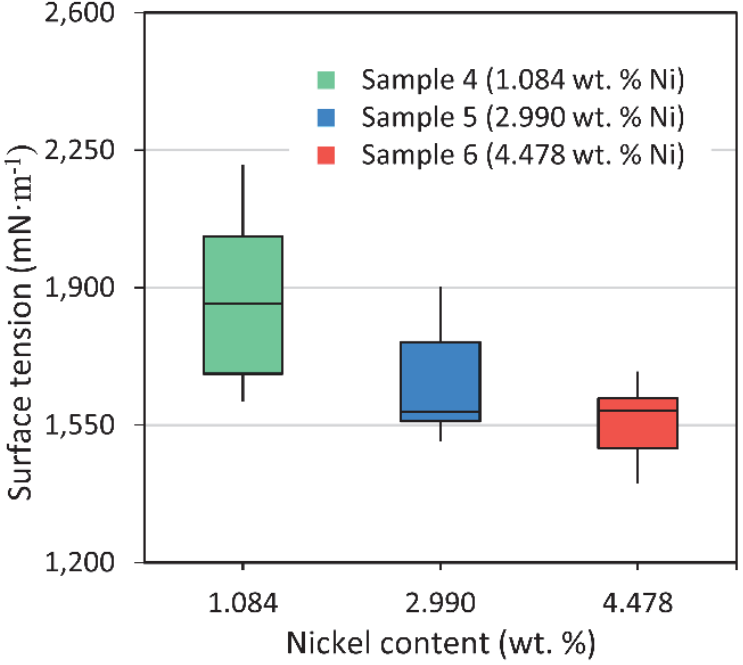

Figure 4 Boxplot of nickel effect on surface tension for Fe-C-O-Ni alloys, temperature range 1,500 $1,600^{\circ} \mathrm{C}$

To determine the surface tension, knowledge of density is essential. Figures $\mathbf{5}$ and $\mathbf{6}$ show temperature dependencies of average experimentally obtained densities. The given dependencies have a decreasing trend for all samples, and thus, the temperature coefficient of density is negative (see Table 2). The temperature dependence of density can be described using equation (2).

$\rho(T)=\rho_{\text {ref }}+\frac{d \rho}{d T} \cdot\left(T-T_{\text {ref }}\right)$

where $\rho_{\text {ref }}\left(\mathrm{g}^{\cdot} \mathrm{cm}^{-3}\right)$ refers to density at reference temperature $T_{\text {ref }}\left({ }^{\circ} \mathrm{C}\right)$ and $d \rho / d T\left(\mathrm{~g}^{\cdot} \mathrm{cm}^{-3 \cdot{ }^{\circ}} \mathrm{C}^{-1}\right)$ is the appropriate temperature coefficient of density. Resulting parameters are presented in Table 2.

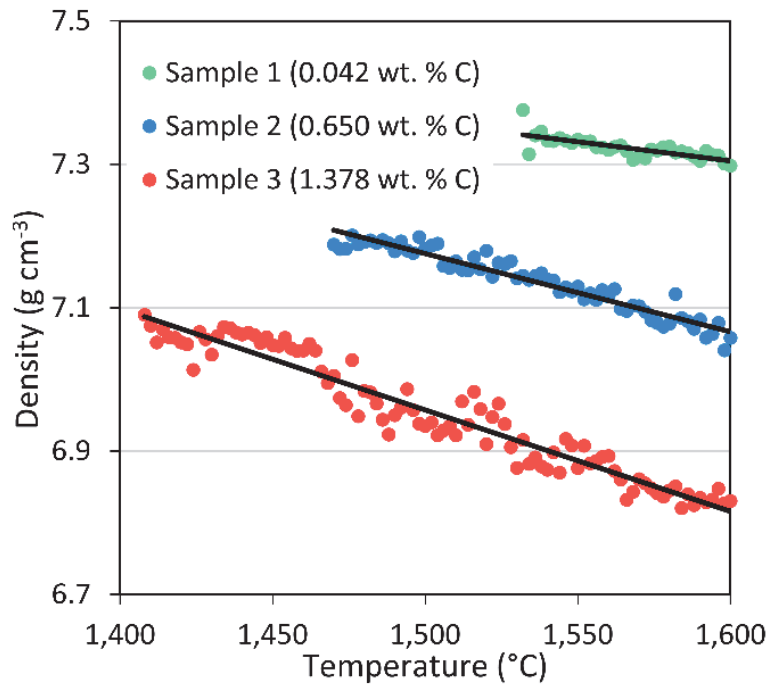

Figure 5 Temperature dependencies of average density for Fe-C-O-Cr alloys

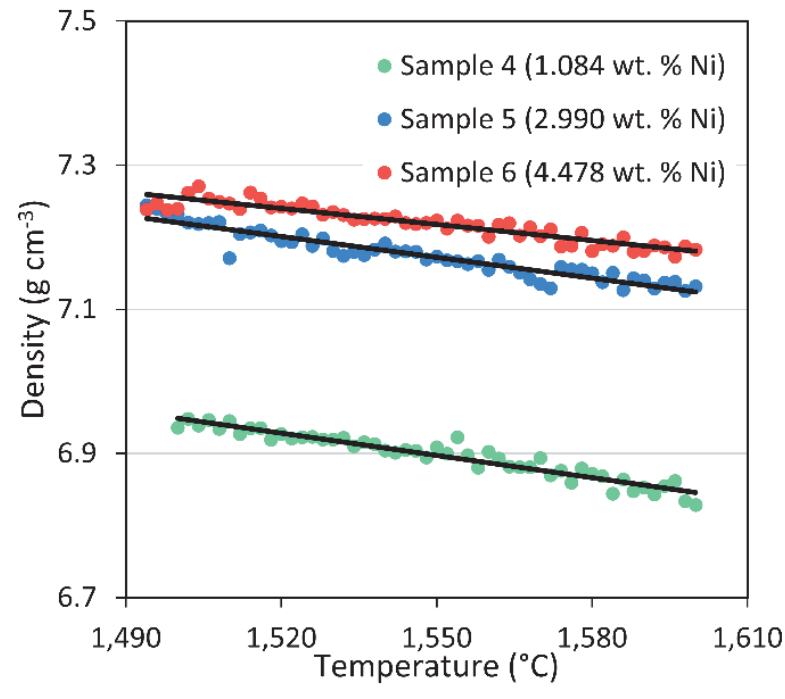

Figure 6 Temperature dependencies of average density for Fe-C-O-Ni alloys

Experimentally determined temperature dependencies of the densities were compared with those calculated by Thermo-Calc software operating with commercially available thermodynamic database TCFE8: TCS Steels / Fe-alloys Database. The database applies to various types of steels / Fe-alloys with an iron minimum of $50 \mathrm{wt} . \%$ and recommended content of certain alloying elements. Figures $\mathbf{7}$ and $\mathbf{8}$ show a comparison of the 
theoretically calculated and experimentally determined densities. Concerning samples 1 - 3 (see Figure 7), the smallest difference between them is for sample 3 having the relative error $0.1 \%$ at $T_{\min }$ and $0.8 \%$ at $T_{\max }$, whereas, the highest difference is achieved for sample 1, where the relative error at $T_{\min }$ is $5.8 \%$ and at $T_{\max }$ is $5.3 \%$. From Figure 8 (assessing samples $4-6)$ is evident that the smallest difference is for sample $4(1.6 \%$ at $T_{\min }$ and $2.0 \%$ at $T_{\max }$ ) and the largest for sample $6\left(2.0 \%\right.$ at $T_{\min }$ and $2.8 \%$ at $\left.T_{\max }\right)$. Besides, the relative error is not higher than $6 \%$ for all samples.

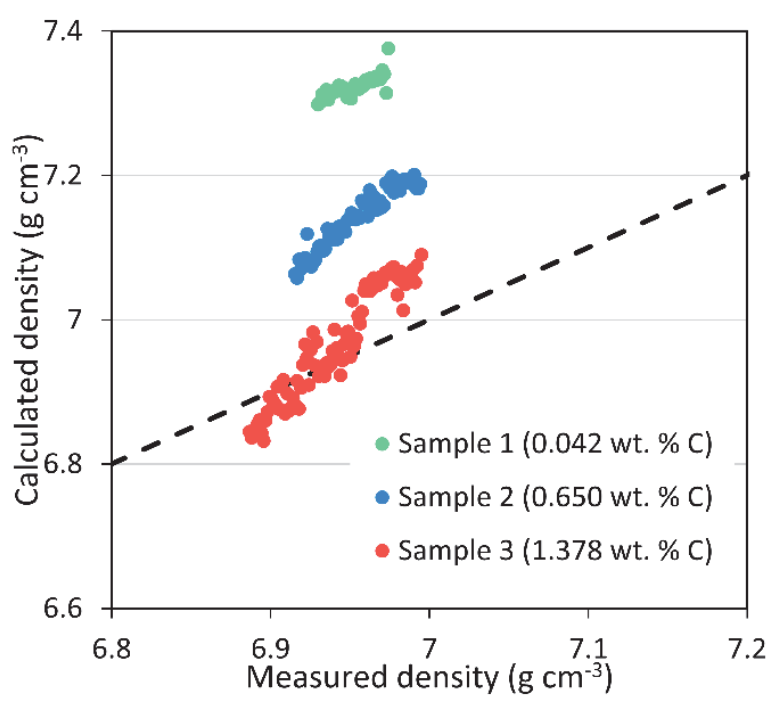

Figure 7 Comparison of measured and calculated densities for Fe-C-O-Cr alloys

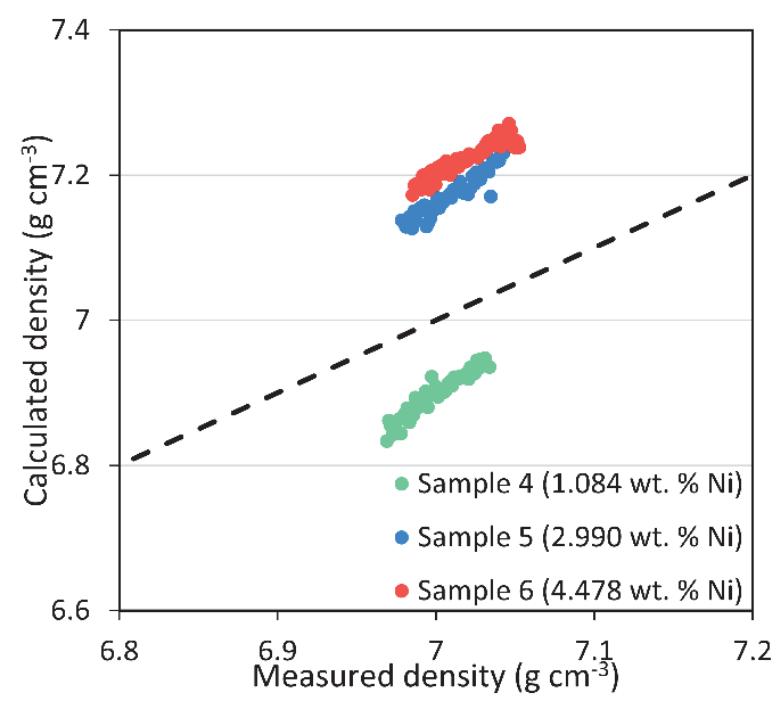

Figure 8 Comparison of measured and calculated densities for Fe-C-O-Ni alloys

Since the surface tension was experimentally investigated using a sessile drop method, the contact angles between alloy and alumina substrate were also determined. Figures $\mathbf{9}$ and $\mathbf{1 0}$ show temperature dependencies of average wetting angles for all alloy samples. Average values of wetting angles increase very slightly with increasing temperature. As can be seen from the course of the dependencies, the wetting angles are also influenced by the carbon and nickel content. As carbon content increases, average wetting angles increase. They lessen with the rise of nickel content.

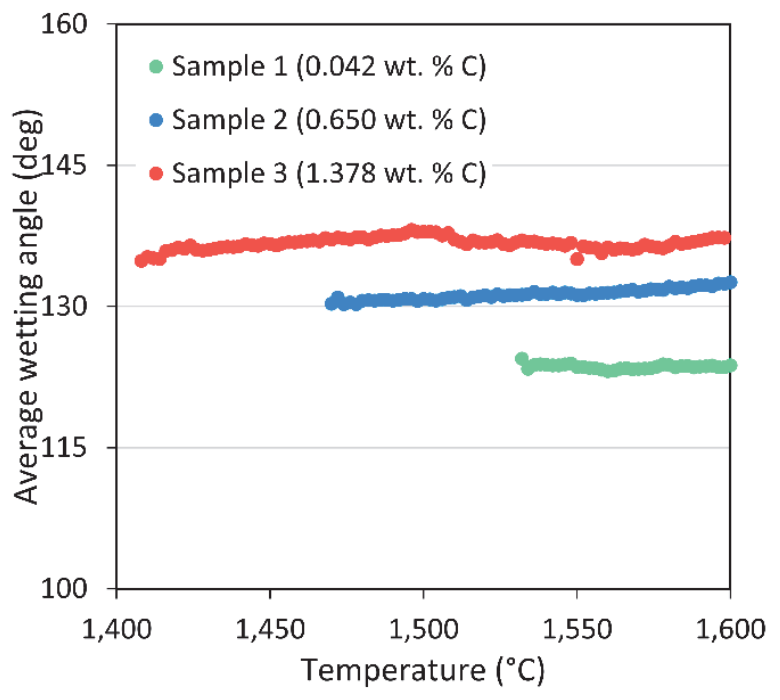

Figure 9 Dependencies of average wetting angle on temperature for $\mathrm{Fe}-\mathrm{C}-\mathrm{O}-\mathrm{Cr}$ alloys

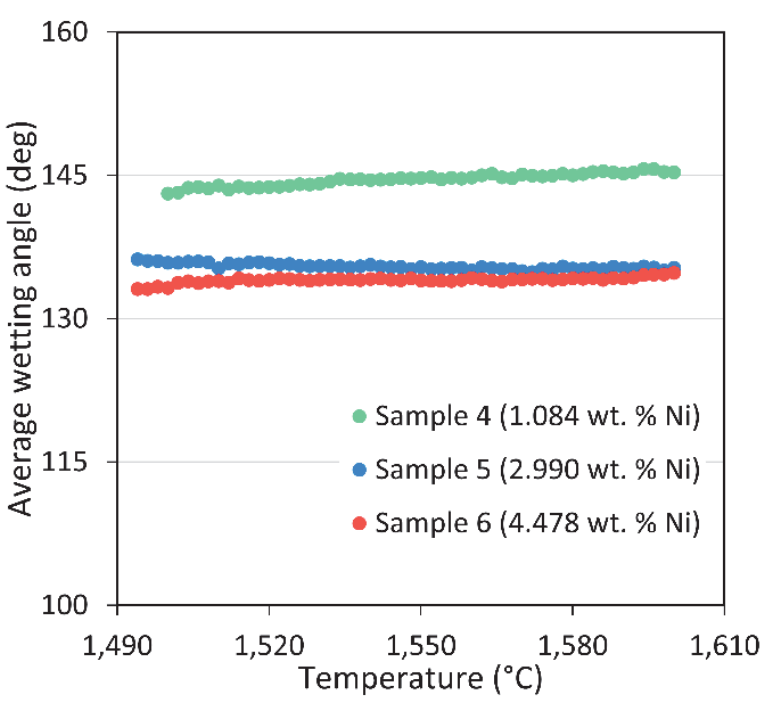

Figure 10 Dependencies of average wetting angle on temperature for Fe-C-O-Ni alloys 


\section{CONCLUSION}

Two series of model alloys Fe-C-O-X $(X=\mathrm{Cr}, \mathrm{Ni})$ differing in carbon and nickel contents were subjected to experimental study. The surface properties and densities were determined in the temperature range from a liquidus temperature of given alloys to the temperature of $1,600^{\circ} \mathrm{C}$. The following results were obtained:

- $\quad$ The surface tension of all investigated alloys depends on temperature. It increases with increasing temperature, and therefore, the temperature coefficient of surface tension $(d \sigma / d T)$ has always been positive.

- The composition affects the surface tension of investigated alloy samples. The larger the carbon content of between 0.043 and $1.378 \mathrm{wt} . \%$, the higher the surface tension was. Regarding the influence of nickel in the given concentration range of $1.084-4.478 \mathrm{wt} . \%$, its influence was opposite to that of carbon.

- $\quad$ There was found a linear decrease in experimentally determined densities with increasing temperature. Comparison between experimental data and theoretical calculations performed by software ThermoCalc showed that the maximum deviation of the theoretical and experimental densities expressed by relative error was not higher than $6 \%$.

- $\quad$ The magnitude of average wetting angle, i.e. the contact angle between the alloy sample and alumina substrate, increased modestly with rising temperature and also depended on the carbon and nickel content of analyzed samples. It increased with increasing carbon content and decreased with increasing nickel content.

\section{ACKNOWLEDGEMENTS}

This paper was created within the frame of the project GACR reg. number 17-18668S and students projects SP2019/90, SP2019/74, SP2019/43 (Faculty of Materials Science and Technology) and "Support of gifted students of doctoral studies at VŠB-TUO" no.: 04766/2017/RRC (Moravian-Silesian Region).

\section{REFERENCES}

[1] LEE, Joonho and MORITA, Kazuki. Effect of carbon and sulphur on the surface tension of molten iron. Process Metallurgy. 2002. vol. 73, no. 9, pp. 367 - 372.

[2] MOROHOSHI, Keisuke, UCHIKOSHI, Masahito, ISSHIKI, Minoru and FUKUYAMA, Hiroyuki. Effects of carbon and oxygen on Fe-C-O melt surface tension. ISIJ International. 2013. vol. 53, no. 8, pp. 1315 - 1319.

[3] KAWAI, Yasuji, MORI, Katsumi, KISHIMOTO, Makoto, ISHIKURA, Katsuhiko and SHIMADA, Toshiro. Surface tension of liquid Fe-C-Si alloys. Tetsu - To - Hagane. 1974. vol. 60, no. 1, pp. 29 - 37.

[4] JIMBO, Itaru and CRAMB, Alan W. Computer aided interfacial measurements. ISIJ International. 1992. vol. 32, no. 1 , pp. 26 - 35.

[5] McNALLAN, Michael J. and DEBROY, Tarasankar. Effect of temperature and composition on surface tension in Fe-Ni-Cr alloys containing sulfur. Metallurgical Transactions B. 1991. vol. 22, no. 4, pp. 557-560.

[6] XIAO, Feng, LIU, Lan-xiao, YANG, Ren-hui, ZHAO, Hong-kai, FANG, Liang and ZHANG, Chi. Surface tension of molten Ni-(Cr, Co, W) alloys and segregation of elements. Transactions of Nonferrous Metals Society of China. 2008. vol. 18, no.5, pp. 1184-1188.

[7] SCHICK, Michael, KHAN, Wajahat, HACK, Klaus and EGRY, Iván. Surface tension of binary NiCr alloys. High Temperatures - High Pressures. 2011. vol. 40, no. 2, pp. 113-125.

[8] SEYHAN, I. and EGRY, Iván. The surface tension of undercooled binary iron and nickel alloys and the effect of oxygen on the surface tension of Fe and Ni. International Journal of Thermophysics. 1999. vol. 20, no. 4, pp. 1017-1028.

[9] SHARAN, A. and CRAMB, Alan W. Surface tension and wettability studies of liquid Fe-Ni-O alloys. Metallurgical and Materials Transactions B. 1997. vol. 28, no.3, pp. 465-472.

[10] DUBBERSTEIN, Tobias, HELLER, Hans P., KLOSTERMANN, Jens, SCHWARZE, Rüdiger and BRILLO, Jürgen. Surface tension and density data for Fe-Cr-Mo, Fe-Cr-Ni, and Fe-Cr-Mn-Ni steels. Journal of Materials Science. 2015. vol. 50, no. 22, pp. 7227-7237. 